\title{
CHEMICAL COMPOSITION OF CARBON DISULFIDE-EXTRACTABLE FRACTION FROM OIL SHALES OF THREE CHINESE DEPOSITS
}

\author{
JING-PEI CAO $^{(\text {a) }}$, ZHI-MIN ZONG ${ }^{(\text {a) }}$, XIAO-YAN ZHAO ${ }^{(\text {a) }}$,

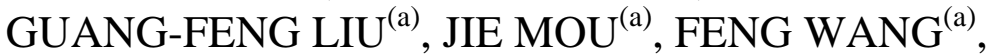 \\ YAO-GUO HUANG ${ }^{(\text {a) }}$, GUO-JIANG ZHOU ${ }^{(\mathrm{b})}$, \\ HAO-QUAN HU ${ }^{(\mathrm{c})}$, XIAN-YONG WEI ${ }^{(\mathrm{a}, \mathrm{b}) *}$
}

(a) School of Chemical Engineering

China University of Mining and Technology

Xuzhou 221008, Jiangsu, China

(b) Institute of Coal Chemical Engineering

Dalian University of Technology

Dalian 116012, Liaoning, China

(c) School of Resources and Environmental Engineering

Heilongjiang Institute of Science and Technology

Harbin 150027, Heilongjiang, China

Understanding chemical composition of organic matter in oil shales in detail is of importance to both organic geochemistry and efficient utilization of oil shales. Because of low boiling point and good penetrability, carbon disulfide was used for extraction of organic matter from solid fossils. In the present study, oil shale samples from Fushun, Longkou and Huadian deposits of China were extracted with carbon disulfide, and extraction solutions were analyzed with gas chromatography and gas chromatography/mass spectrometry. The results show that alkanes, including a series of normal alkanes, isoprenoids and cyclanes, are predominant in extraction solutions. Other compounds detected in the extraction solutions are alkenes, alkylated arenes and organo-oxygen compounds. Normal alkanes are predominant in the carbon disulfide-extractable fraction $(C D E F)$ from Huadian oil shale. CDEF from Longkou oil shale contains much more alkanes than those from other two oil shales, whereas CDEF from Fushun oil shale contains more cyclanes than those from other two oil shale deposits.

\footnotetext{
*Corresponding author: e-mail weimanuscripts@yahoo.com,weimanuscripts@163.com
} 


\section{Introduction}

Rapid increase in consumption of energy and chemicals leads to dramatic increase in the prices of conventional fossil resources and thereby makes fuel chemists to pay more attention to alternative resources. Oil shales could be promising alternative ones because their reserves are large [1,2] and hydrogen to carbon molar ratio in organic matter is high. Understanding of the composition of organic matter in oil shales is of significance not only to organic geochemistry but also to efficient utilization, especially value-added utilization of them.

Most of the related work, however, have been focused on supercritical fluid extraction, extraction yield and composition of biomarkers [3-8]. Only few researchers [9-13] have paid attention to detailed characterization of molecular structure of oil shales.

Our previous work showed that separable and non-destructive techniques are effective for determination of molecular structures of organic species present in oil shales [14], coals [15-18] and their reaction mixtures [19-21]. Because of its low boiling point and good penetrability in pores of solid fossils such as coals and oil shales, carbon disulfide $\left(\mathrm{CS}_{2}\right)$ was used as an effective solvent for extracting aliphatic and aromatic hydrocarbons of lower molecular mass [14-18]. Using the techniques, we investigated the composition of organic species in carbon disulfide-extractable fraction (CDEF) from three Chinese oil shales.

\section{Experimental}

\section{Solvent and oil shale samples}

$\mathrm{CS}_{2}$ used as the solvent in the experiment is an analytical-pure reagent and distilled before use. GC/MS analysis shows no species in the distilled solvent except for $\mathrm{CS}_{2}$ itself.

Oil shales (OSSs) used in the experiment were taken from the following deposits: Fushun (FS), Longkou (LK) and Huadian (HD), China, pulverized to pass through a 200 -mesh screen and dried in vacuum at $80^{\circ} \mathrm{C}$ for $24 \mathrm{~h}$ before use. Table 1 shows the proximate and ultimate analyses of the OSSs.

Table 1. Proximate and ultimate analyses (wt.\%) of OSSs ${ }^{*}$

\begin{tabular}{|c|c|c|c|c|c|c|c|}
\hline \multirow{2}{*}{ Oil shale deposit } & \multicolumn{3}{|c|}{ Proximate analysis } & \multicolumn{3}{|c|}{ Ultimate analysis (daf) } & \multirow{2}{*}{$\mathrm{S}_{\mathrm{t}, \mathrm{d}}$, wt.\% } \\
\hline & $\mathrm{M}_{\mathrm{ad}}$ & $\mathrm{A}_{\mathrm{ad}}$ & $\mathrm{V}_{\text {daf }}$ & $\mathrm{C}$ & $\mathrm{H}$ & $\mathrm{N}$ & \\
\hline Fushun & 2.10 & 76.1 & 88.5 & 42.1 & 8.8 & 2.1 & 2.6 \\
\hline Longkou & 11.6 & 35.0 & 59.7 & 76.1 & 7.5 & 0.4 & 2.4 \\
\hline Huadian & 7.8 & 60.8 & 86.0 & 66.2 & 10.4 & 1.3 & 3.3 \\
\hline
\end{tabular}

Data for proximate and ultimate analyses were obtained with Leco Mac-400 Thermogravimetric Analyzer, Leco CHN-2000 Elemental Determinator and Leco SC-132 Sulfur Determinator, respectively. 


\section{FTIR analysis}

Organic groups of OSSs were characterized using a Nicolet Magna IR-560 FTIR. The FTIR spectra were generated by collecting 50 scans at a resolution of $8 \mathrm{~cm}^{-1}$ in reflectance mode. Measuring regions were $4000-500 \mathrm{~cm}^{-1}$. Figure 1 displays FTIR spectra of OSSs.

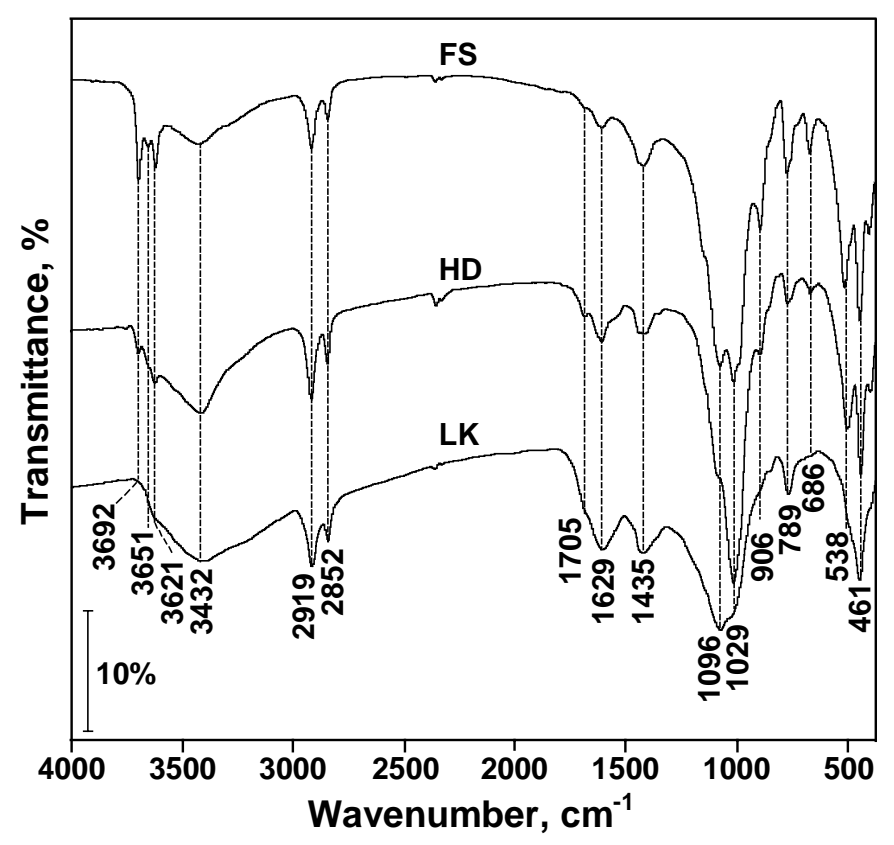

Fig. 1. FTIR spectra of OSSs.

\section{Extraction with $\mathrm{CS}_{\mathbf{2}}$ and analysis of the extracts using GC/MS}

Each OSS was extracted with $300 \mathrm{~mL}$ of $\mathrm{CS}_{2}$ under the nitrogen atmosphere in a Soxhlet extractor during at least 10 days. The extraction solution was concentrated to $c a 1 \mathrm{~mL}$ using a rotary evaporator, and $c a 0.5 \mu \mathrm{L}$ of the concentrated solution was analyzed using a Hewlett-Packard 6890/5973 GC/MS equipped with a capillary column coated with HP-5MS (30 $\mathrm{m} \times 0.25 \mathrm{~mm}$ inner diameter (ID), film thickness of $0.25 \mu \mathrm{m}$ ) and with a Hewlett-Packard 6890 GC equipped with a capillary column coated with HP-101 (30 m×0.32 mm ID, film thickness of $0.3 \mu \mathrm{m})$. The columns were heated at a rate of $10{ }^{\circ} \mathrm{C} / \mathrm{min}$ from $100{ }^{\circ} \mathrm{C}$ (and held at the temperature for $2 \mathrm{~min}$ ) to $300^{\circ} \mathrm{C}$ (and held at temperature for $5 \mathrm{~min}$ ). Both injector and detector temperatures were set at $300{ }^{\circ} \mathrm{C}$. Mass spectra were obtained at an electron impact potential of $70 \mathrm{eV}$ within a range of 30-500 amu. A series of authentic compounds purchased from Aldrich Chemical Co., Inc. was used for confirmation and quantification of the compounds identified with GC/MS. The yields (wt.\%, daf) of extracts in the OSSs from FS, LK and HD were 7.1, 4.2 and 8.9, respectively. 


\section{Results and discussion \\ FTIR analysis of OSSs}

As shown in Fig. 1 and Table 2, OSS from HD contains much more aliphatic moieties (AM) along with more carboxylic moieties than those from LK and FS. The content of free hydroxyl groups and epoxide along with aromatic moiety in the OSSs decreases in the order: FS > HD > LK. OSSs from HD and LK contain more alkenyl moiety than that from FS. There is more alkanol moiety in OSSs from FS and LK than in that from HD. Silicate content in OSSs decreases in the order: FS > HD $>$ LK, just being consistent with the order of their ash content.

Table 2. Structural features of OSSs characterized by FTIR

\begin{tabular}{|c|c|c|c|c|}
\hline \multirow{2}{*}{ Wavenumber, $\mathrm{cm}^{-1}$} & Assignment & \multicolumn{3}{|c|}{ Oil shale } \\
\cline { 2 - 5 } & & Fushun & Huadian & Longkou \\
\hline $3692,3651,3621$ & $-\mathrm{OH}$ (free) & $\mathrm{S}$ & $\mathrm{O}$ & $\mathrm{VW}$ \\
3432 & $-\mathrm{OH}$ (bonded) & $\mathrm{S}$ & $\mathrm{S}$ & $\mathrm{S}$ \\
$2919,2852,1435$ & $\mathrm{CH}_{3^{-}},-\mathrm{CH}_{2^{-}}$ & $\mathrm{S}$ & $\mathrm{VS}$ & $\mathrm{S}$ \\
1705 & $-\mathrm{COOH}$ & $\mathrm{VW}$ & $\mathrm{W}$ & $\mathrm{VW}$ \\
1629 & $>\mathrm{C}=\mathrm{C}<$ & $\mathrm{O}$ & $\mathrm{S}$ & $\mathrm{S}$ \\
1096 & $>\mathrm{C}-\mathrm{OH}($ alcohols $)$ & $\mathrm{VS}$ & $\mathrm{VS}$ & $\mathrm{VS}$ \\
1029,461 & $\mathrm{Silicates}$ & $\mathrm{VS}$ & $\mathrm{VS}$ & $\mathrm{VS}$ \\
906 & Epoxide & $\mathrm{S}$ & $\mathrm{S}$ & $\mathrm{N}$ \\
789,686 & $\mathrm{C}-\mathrm{H}(m$-disubstituted benzene) $(\mathrm{Obv})$ & $\mathrm{S}$ & $\mathrm{O}$ & $\mathrm{O}$ \\
538 & $-\mathrm{CH}_{2} \mathrm{Br}$ & $\mathrm{VS}$ & $\mathrm{VS}$ & $\mathrm{VW}$ \\
\hline
\end{tabular}

VS: very strong; S: strong; O: ordinary; W: weak; VW: very weak; N: none; Obv: Out-ofplane bending vibration

Interestingly, a remarkable and appreciable amount of $-\mathrm{CH}_{2} \mathrm{Br}$ moiety can be observed in FTIR spectra of OSSs from FS and HD, but no organobromines were detected in CDEFs from FS and HD using GC/MS, implying that the $-\mathrm{CH}_{2} \mathrm{Br}$ moiety in both OSS may exist as organic macromolecular species.

\section{GC/MS analysis}

Figure 2 shows total ion chromatograms (TICs) of all CDEFs. The compounds identified fall into the following categories: normal alkanes (NAs), isoprenoids (IPs), cyclanes, alkenes, alkylated arenes (AAs) and organooxygen compounds (OOCs), as listed in Tables 3 to 8, respectively.

Organic compounds (OCs) identified in CDEFs account for $15.12 \%$ from FS, $13.75 \%$ from HD and $7.34 \%$ from LK, suggesting that OCs identified in CDEFs are only a minority, and majority of CDEFs may consist of macromolecular and/or strongly polar species, which cannot be detected with GC/MS. 


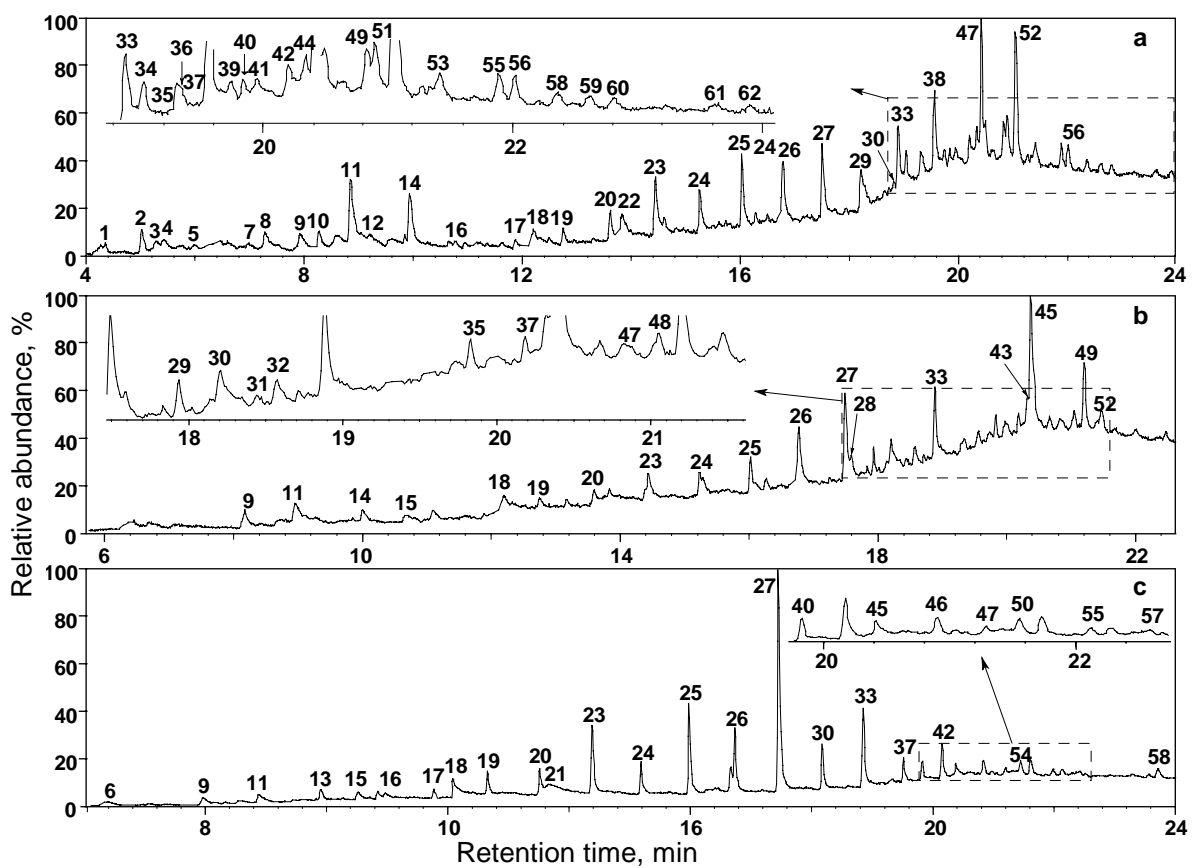

Fig. 2. TICs of CDEFs from FS (a), LK (b) and HD (c).

As shown in Figs. 3-5, alkanes are predominant in all CDEFs, and NAs are main components detected in CDEFs from HD and LK. The amounts of alkenes detected in CDEF from LK were much larger than those in CDEFs from HD and LK. The total yield of AAs in CDEF from FS is higher than that in CDEF from LK, while no AAs were observed in CDEF from HD. The total yield of OOCs detected in CDEF from HD is higher than that in those from FS and LK.

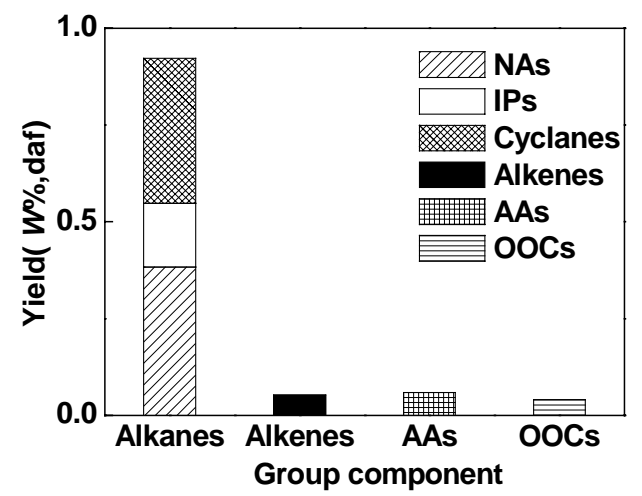

Fig. 3. Yields of group components detected in CDEF from FS. 


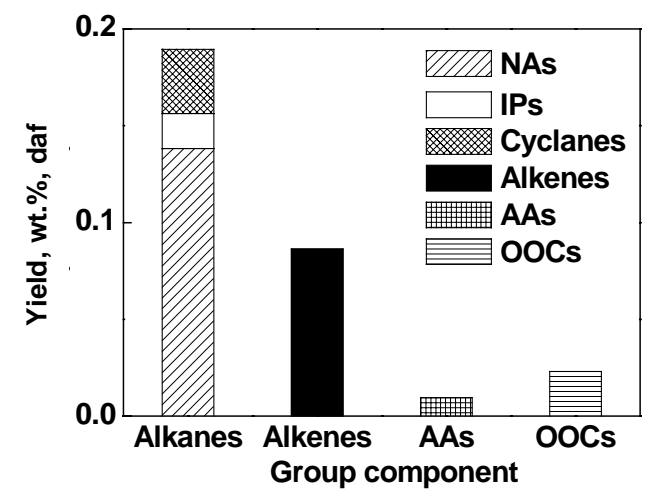

Fig. 4. Yields of group components detected in CDEF from LK.

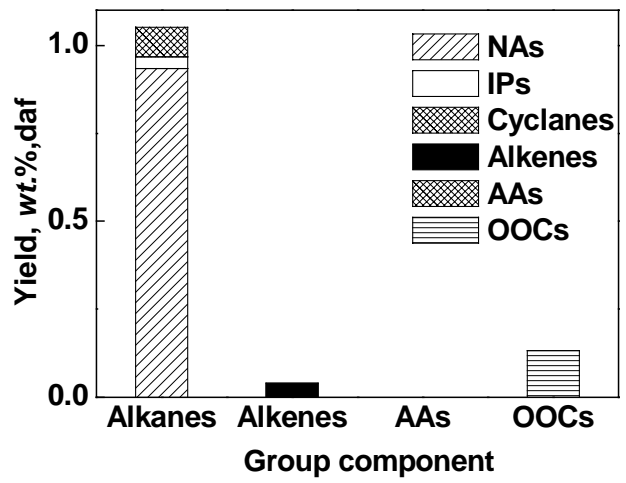

Fig. 5. Yields of group components detected in CDEF from HD.

As Fig. 6 illustrates, cyclanes and NAs are the largest group components in CDEFs from FS and LK respectively, whereas NAs are predominant in CDEF from HD.

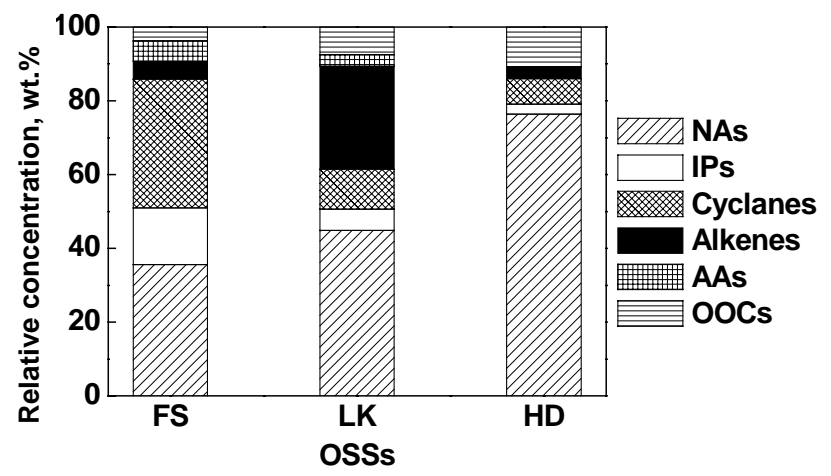

Fig. 6. Distributions of group components detected in CDEFs from the OSSs. 
NAs. In total, seventeen NAs, from $\mathrm{C}_{16}$ to $\mathrm{C}_{33}$, were detected in CDEFs (Table 3), and all NAs were observed in CDEF from HD (Fig. 2c). Most of compounds detected are NAs, and heptacosane is predominantly abundant as a single compound in CDEF from HD. NAs are also primary components in CDEF from LK (Fig. 2b), but secondary ones in CDEF from FS (Fig. 2a). Much lower concentration of NAs with carbon number below 20 in CDEFs indicates that catalytic hydrocracking is necessary for converting the extracts to a clean liquid fuel.

Table 3. Yields of NAs detected in CDEFs

\begin{tabular}{|c|l|r|c|c|}
\hline \multirow{2}{*}{ No. } & \multirow{2}{*}{ Compound } & \multicolumn{3}{|c|}{ Yield, $\mu \mathrm{g} / \mathrm{g}$ OSS, daf } \\
\cline { 3 - 5 } & & Fushun & Longkou & Huadian \\
\hline 6 & Hexadecane & & & 119.8 \\
13 & Octadecane & & & 169.3 \\
16 & Nonadecane & 83.2 & & 129.7 \\
17 & Eicosane & 80.5 & & 110.8 \\
19 & Heneicosane & 157.1 & 47.1 & 265.1 \\
20 & Docosane & 221.2 & 65.5 & 327.4 \\
23 & Tricosane & 472.3 & 170.9 & 781.7 \\
24 & Tetracosane & 362.8 & 89.6 & 428.4 \\
25 & Pentacosane & 513.8 & 116.7 & 997.3 \\
26 & Hexacosane & 485.0 & 198.1 & 663.6 \\
27 & Heptacosane & 575.5 & 279.6 & 2628.1 \\
30 & Octacosane & 303.5 & 152.8 & 537.8 \\
33 & Nonacosane & 358.6 & 212.6 & 993.5 \\
37 & Triacontane & 87.9 & 48.4 & 297.9 \\
42 & Hentriacontane & 127.8 & & 480.3 \\
46 & Dotriacontane & & & 191.1 \\
54 & Tritriacontane & & & 221.8 \\
\hline
\end{tabular}

IPs. In total, five IPs, from $\mathrm{C}_{15}$ to $\mathrm{C}_{20}$, were detected in CDEFs (Table 4) and all IPs were observed from CDEF from FS (Fig. 2a). Pristane and phytane predominate in IPs, being the only two IPs in CDEF from LK, while pristane is the only IP detected in CDEF from HD.

Table 4. Yields of IPs detected in CDEFs

\begin{tabular}{|r|l|c|c|c|}
\hline \multirow{2}{*}{ No. } & \multicolumn{2}{|c|}{ Compound } & \multicolumn{3}{|c|}{ Yield, $\mu \mathrm{g} / \mathrm{g}$ OSS, daf } \\
\cline { 3 - 5 } & & Fushun & Longkou & Huadian \\
\hline 3 & 2,6,10-Trimethyldodecane & 102.5 & & \\
5 & 2,6,10-Trimethyltridecane & 162.5 & & \\
10 & 2,6,10-Trimethylpentadecane & 155.5 & & \\
11 & Pristane & 723.1 & 119.7 & 330.1 \\
14 & Phytane & 502.8 & 60.5 & \\
\hline
\end{tabular}


Cyclanes. Totally twenty five cyclanes were identified in CDEFs (Table 5), including two bicyclic sesquiterpanes, six cholestanes, sixteen hopanes in addition to $17 \beta \mathrm{H}, 21 \alpha \mathrm{H}$-normoretane. Twenty one of them were observed in CDEF from FS (Fig. 2a) and 17 $\alpha \mathrm{H}-22,29,30$-trisnorhopane and $17 \alpha \mathrm{H}, 21 \beta \mathrm{H}$-hopane are predominantly abundant, while only five cyclanes were found in CDEF from LK (Fig. 2b), 17 $\beta \mathrm{H}, 21 \beta \mathrm{H}-30$-norhopane being the most abundant one. As a possible product at thermolysis of pentacyclic triterpanes [22], 8,14-seco-hopane was detected only in CDEF from LK. The number of cyclanes detected in CDEF from HD is also five, but all the cyclanes differ from those detected in CDEF from LK and their concentration is much lower.

Alkenes. In all, five alkenes were identified in CDEFs (Table 6), including three hopenes and two disasterenes. All five were detected in CDEF from LK (Fig. 2b) and 30-norneohop-13(18)-ene was detected in CDEF from HD. Noteworthily, 30-norneohop-17(21)-ene is the most abundant compound in CDEF from LK. Only one alkene occurs in CDEF from HD (Fig. 2c) except for 30-norneohop-13(18)-ene.

Table 5. Yields of cyclanes detected in CDEFs

\begin{tabular}{|c|c|c|c|c|}
\hline \multirow{2}{*}{ No. } & \multirow{2}{*}{ Compound } & \multicolumn{3}{|c|}{ Yield, $\mu \mathrm{g} / \mathrm{g}$ OSS, daf } \\
\hline & & Fushun & Longkou & Huadian \\
\hline 1 & $\mathrm{C}_{13}$-bicyclic sesquiterpane & 146.1 & & \\
\hline 2 & $\mathrm{C}_{14}$-bicyclic sesquiterpane & 217.6 & & \\
\hline 34 & Cholestane & 133.6 & & \\
\hline 35 & $18 \alpha \mathrm{H}-22,29,30$-Trisnorneohopane & 205.7 & 59.2 & \\
\hline 36 & $14 \alpha$-Methylcholestane & 21.4 & & \\
\hline 38 & $17 \alpha \mathrm{H}-22,29,30$-Trisnorhopane & 305.9 & & \\
\hline 39 & 24-Methyl-5 $\alpha \mathrm{H}$-cholestane & 89.4 & & \\
\hline 40 & $17 \beta$ H-22,29,30-Trisnorhopane & 81.1 & & 251.3 \\
\hline 41 & 24-Ethyl-5 $\beta \mathrm{H}$-Cholestane & 81.9 & & \\
\hline 43 & 8,14-seco-Hopane & & 63.4 & \\
\hline 44 & 24-Ethyl-5 $\alpha \mathrm{H}$-Cholestane & 85.9 & & \\
\hline 48 & $17 \alpha \mathrm{H}, 21 \beta \mathrm{H}-30$-Norhopane & 523.0 & 61.4 & \\
\hline 49 & $17 \beta \mathrm{H}, 21 \beta \mathrm{H}-30-$ Norhopane & 181.3 & 70.3 & \\
\hline 50 & $17 \beta \mathrm{H}, 21 \alpha \mathrm{H}-$ Normoretane & & & 216.3 \\
\hline 51 & Trimethylcholestane & 194.0 & & \\
\hline 52 & $17 \alpha \mathrm{H}, 21 \beta \mathrm{H}-\mathrm{Hopane}$ & 873.1 & 77.9 & \\
\hline 53 & $17 \beta \mathrm{H}, 21 \beta \mathrm{H}-\mathrm{Hopane}$ & 150.3 & & \\
\hline 55 & $17 \alpha \mathrm{H}, 21 \beta \mathrm{H}-22 \mathrm{~S}-\mathrm{Homohopane}$ & 181.8 & & 99.9 \\
\hline 56 & $17 \alpha \mathrm{H}, 21 \beta \mathrm{H}-22 \mathrm{R}-\mathrm{Homohopane}$ & 182.4 & & \\
\hline 57 & $17 \beta \mathrm{H}, 21 \alpha \mathrm{H}-\mathrm{Hopane}$ & & & 95.4 \\
\hline 58 & $17 \beta \mathrm{H}, 21 \alpha \mathrm{H}-\mathrm{Homohopane}$ & 108.1 & & 182.2 \\
\hline 59 & $17 \alpha \mathrm{H}, 21 \beta \mathrm{H}-22 \mathrm{~S}-\mathrm{Bishomohopane}$ & 99.1 & & \\
\hline 60 & $17 \alpha \mathrm{H}, 21 \beta \mathrm{H}-22 \mathrm{R}-\mathrm{Bishomohopane}$ & 101.6 & & \\
\hline 61 & $17 \alpha \mathrm{H}, 21 \beta \mathrm{H}-22 \mathrm{~S}$-Trishomohopane & 73.5 & & \\
\hline 62 & $17 \alpha \mathrm{H}, 21 \beta \mathrm{H}-22 \mathrm{R}-$ Trishomohopane & 61.3 & & \\
\hline
\end{tabular}




\section{Table 6. Yields of alkenes detected in all CDEFs}

\begin{tabular}{|c|l|c|c|}
\hline \multirow{2}{*}{ No. } & \multicolumn{2}{|c|}{ Compound } & \multicolumn{2}{|c|}{ Yield, $\mu \mathrm{g} / \mathrm{g}$ OSS, daf } \\
\cline { 3 - 4 } & & Longkou & Huadian \\
\hline 28 & Hopene & 91.1 & \\
29 & 24S-Ethyl disaster-13(17)-ene & 80.7 & \\
32 & 24R-Ethyl disaster-13(17)-ene & 96.6 & \\
45 & 30-Norneohop-17(21)-ene & 414 & 277.1 \\
47 & 30-Norneohop-13(18)-ene & 180.4 & 122.4 \\
\hline
\end{tabular}

AAs. Totally five AAs were detected (Table 7), including alkyl-substituted tetralins (peaks 4 and 8), naphthalene (peak 12) and diphenylmethane (peak 22) along with a sterane (peak 31). All of them appear in CDEF from FS (Fig. 2a) and one in CDEF from LK (Fig. 2b), but there is no $\mathrm{AA}$ in $\mathrm{CDEF}$ from HD. The concentration of all the AAs detected is low.

Table 7. Yields of ASAs detected in CDEFs

\begin{tabular}{|r|l|c|c|}
\hline \multirow{2}{*}{ No. } & \multicolumn{1}{|c|}{ Compound } & \multicolumn{2}{|c|}{ Yield, $\mu \mathrm{g} / \mathrm{g}$ OSS, daf } \\
\cline { 3 - 4 } & & Fushun & Longkou \\
\hline 4 & 1,1,6-Trimethyltetralin & 125.8 & \\
8 & 5,6,7,8-Tetramethyltetralin & 169.3 & \\
12 & Cadalene & 84.4 & \\
22 & 1,1 '-Di(2,3-xylyl)ethane & 212.1 & \\
31 & C $_{27}$-Monoaromatic sterane & 166.8 & 95.6 \\
\hline
\end{tabular}

OOCs. In all, five OOCs were detected in CDEFs (Table 8), including a phenol (peak 7), two esters (peaks 9 and 18), an alkanone (peak 15) and an alkanoic acid (peak 21). Both esters appear in all CDEFs, and the alkanone was detected in CDEFs from both LK and HD.

\section{Table 8. Yields of OOCs detected in the CDEFs}

\begin{tabular}{|c|l|c|c|c|}
\hline \multirow{2}{*}{ No. } & \multicolumn{1}{|c|}{ Compound } & \multicolumn{3}{|c|}{ Yield, $\mu \mathrm{g} / \mathrm{g}$ OSS, daf } \\
\cline { 3 - 5 } & & Fushun & Longkou & Huadian \\
\hline 7 & 3-Methyl-1,5-di(tert-butyl)phenol & 81.1 & & \\
9 & BTMPMM & 244.0 & 65.1 & 211.4 \\
15 & 6,10,14-Trimethyl-2-pentadecanone & & 57.7 & 173.9 \\
18 & Isopropyl palmitate & 80.7 & 108.6 & 301.7 \\
21 & Stearic acid & & & 631.8 \\
\hline
\end{tabular}

BTMPMM: bis(2,2,4-trimethylpentan-3-yl) 2-methylmalonate. 


\section{Conclusions}

The yield (wt.\%, daf) of extract and the share of GC/MS-detectable species in the OSS from LK are lower than corresponding characteristics of samples from FS and $\mathrm{HD}$. $\mathrm{CS}_{2}$-extractable fractions of three Chinese oil shales mainly consist of alkanes along with small amounts of alkenes, aromatic ring- and oxygen-containing compounds. Large amounts of NAs and cyclanes along with small amounts of IPs, alkenes, AAs and OOCs are detected in CDEF from FS. OCs detected in CDEF from LK mainly consist of NAs and alkenes, in which 30-norneohop-17(21)-ene is the most abundant compound. NAs (from $\mathrm{C}_{16}$ to $\mathrm{C}_{33}$ ) are predominant in CDEF from $\mathrm{HD}$, whereas no AAs are observed in this extract. The amount of OOCs detected in CDEF from HD is much greater than those in extracts from FS and LK.

\section{Acknowledgements}

This work was subsidized by the Special Fund for Major State Basic Research Project (Project 2004CB217801).

\section{REFERENCES}

1. Russell, P. L. Oil shales of the world; their origin, occurrence and exploitation. - Oxford, 1990.

2. Dyni, J. R. Geology and resources of some world oil-shale deposits // Oil Shale. 2003. Vol. 20, No. 3. P. 193-252.

3. Bondar, E., Koel, M. Application of supercritical fluid extraction to organic geochemical studies of oil shales // Fuel. 1998. Vol. 77, No. 3. P. 211-213.

4. Bondar, E., Koel, M. Liiv, M. A comparative study of the composition of biomarkers in SFE and solvent extracts of oil shales // Fuel. 1998. Vol. 77, No. 3. P. 215-218.

5. Platonov, V. V., Proskuryakov, V. A., Glybina, A. V. Chemical composition of the organic matter of oil shale (Kerogen-70) from Leningrad Oblast (BenzeneEthanol extract) // Russ. J. Appl. Chem. 2002. Vol. 75, No. 3. P. 495-498.

6. Anabtawi, M. Z., Uysal, B.Z. Extraction of El-Lajjun oil shale//Sep. Sci. Technol. 1995. Vol. 30, No. 17. P. 3363-3373.

7. Vandegrift, G. F., Winans, R. E., Scott, R. G., et al. Quantitative study of the carboxylic acids in Green River oil shale bitumen // Fuel. 1980. Vol. 59, No. 9. P. 627-633.

8. Blanco, C. G., Prado, J. G., Guillen, M. D., et al. Preliminary results of extraction experiments in an oil shale // Org. Geochem. 1992. Vol. 18, No. 3. P. 313-316.

9. Pais, R., Klesment, I., Pobul, L. Hydrocarbons and oxygen compounds in the bitumen of schist-kukersite // Proc. Estonian Acad. Sci. Chem. 1979. Vol. 28, No. 3. P. 182-190 [in Russian]. 
10. Klesment, I., Kuusik, M., Pobul, L. Characterization of bitumens from Borov Dol oil shale (Bulgaria)// Proc. Estonian Acad. Sci. Chem. 1981. Vol. 30, No. 2. P. 69-74 [in Russian].

11. Pobul, L., Klesment, I., Kuusik, M. Study of the composition and genesis of arpathian menilitic oil shales. I. Composition of bitumen // Proc. Estonian Acad. Sci. Chem. 1981. Vol. 30, No. 4. P. 259-266 [in Russian].

12. Pobul, L., Klesment, I., Kuusik, M. Study of the organic matter of Kenderlyk oil shales. 1. Composition of bitumens and general characterization of oil shales // Proc. Estonian Acad. Sci. Chem. 1982. Vol. 31, No. 1. P. 25-32 [in Russian].

13. Adam, $P$. . Schaeffer, $P .$, Albrecht, $P$. $\mathrm{C}_{40}$ monoaromatic lycopane derivatives as indicators of the contribution of the alga Botryococcus braunii race $\mathrm{L}$ to the organic matter of Messel oil shale (Eocene. Germany) // Org. Geochem. 2006. Vol. 37, No. 5. P. 584-596.

14. Cao, J. P., Zong, Z. M., Zhao, X. Y., et al. Identification of octathiocane, organonitrogens, and organosulfurs in Tongchuan shale // Energy Fuels. 2007. Vol. 21, No. 2. DOI: 10.1021/ef0602776.

15. Wang, X. H., Xiong, Y. C., Gu, X. H., et al. GC/MS analysis of $\mathrm{CS}_{2}$-extracts from several bituminous coals // J. Fuel. Chem. Technol. 2002. Vol. 30, No. 1. P. 72-77 [in Chinese].

16. Wei, X. Y., Wang, X. H., Zong, Z. M., et al. Identification of organochlorines and organobromines in coals // Fuel. 2004. Vol. 83, No. 17-18. P. 2435-2438.

17. Wang, X. H., Wei, X. Y. Study of constituents of fractionated extraction from Datong coal // J. Chin. Univ. Min. Technol. 2005. Vol. 15, No. 4. P. 299-304.

18. Zhao, X. Y., Zong, Z. M., Cao, J. P., et al. Difference in chemical composition of carbon disulfide-extractable fraction between vitrinite and inertinite from Shenfu-Dongsheng and Pingshuo coals //Fuel. 2007 [in press]. doi:10.1016/j.fuel.2007.02.021.

19. Wei, X. Y., Ni, Z. H., Xiong, Y. C., et al. Pd/C-Catalyzed release of organonitrogen compounds from bituminous coals // Energy Fuels. 2002. Vol. 16, No. 2. P. 527-528.

20. Liu, Z.X., Liu, Z. C., Zong, Z. M., et al. GC/MS analysis of water-soluble products from the mild oxidation of Longkou brown coal with $\mathrm{H}_{2} \mathrm{O}_{2}$ // Energy Fuels. 2003. Vol. 17, No. 2. P. 424-426.

21. Sun, L. B., Zong, Z. M., Kou, J. H., et al. Thermal release and catalytic removal of organicSulfur compounds from Upper Freeport coal // Energy Fuels. 2005. Vol. 19, No. 2. P. 339-342.

22. Wang, Z. R., Ma, S. P., Wang, J. L. Organic geochemistry and origin of oil from continental deposits. - Beijing, 1986 [in Chinese].

Presented by Qian Jialin

Received January 11, 2007 